\title{
CALEIDOSCÓPIO DE LUZ INEXPLICÁVEL
}

\author{
Ricardo Marques \\ (Universidade Nova de Lisboa)
}

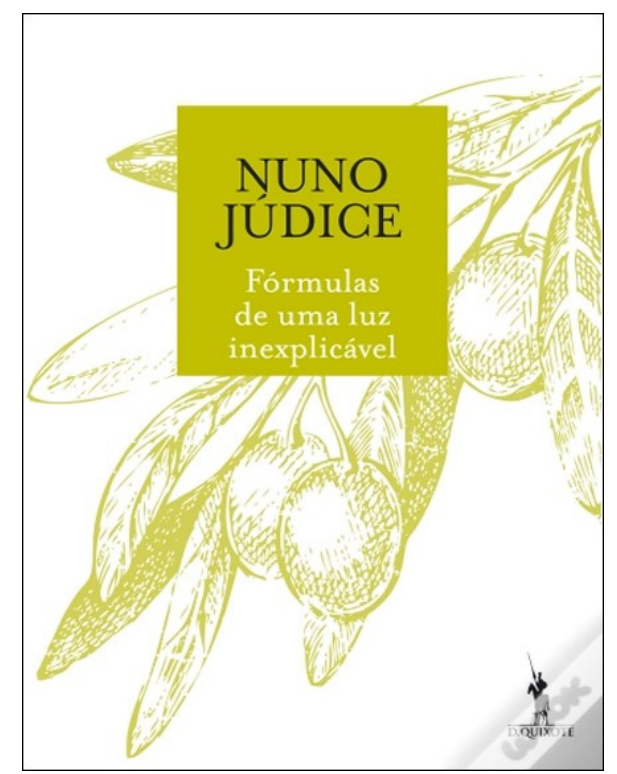

RM: A Poesia Reunida de 2000 mostra-nos um poeta que escreve há 3 décadas e a quem preocupa certos temas recorrentes, mas que os tem vindo a escrever com um estilo mais contido e, talvez, mais limado. O que mudou desde a última poesia reunida, como sente o seu percurso neste início de século?

NJ: Não me costumo reler, e se há temas recorrentes deixo ao crítico o trabalho de os encontrar. Quanto a mudança, vejo a minha poesia como um longo poema que terá começado entre meados e fins da década de 1960, e ainda não acabou. Quanto a mudanças, não há nada pior do que pretender mudar. Escrevo, reescrevo, rasuro: é este o meu trabalho.

(Questionário presente no website poemsfromtheportuguese.org) 
Ainda persiste uma franca, mas sempre utópica, perseguição da originalidade naquilo que se espera de um autor e que depois se reflecte naquilo que se escreve no universo da crítica (portuguesa e não só), como se nunca tivéssemos passado pelo século XX, por um autointitulado modernismo tantas vezes oco e pelas suas múltiplas reinvenções revivalistas, que uma simples frase de Maurice Blanchot resume no simbólico ano de 1969 - "Ce qui importe, ce n'est pas de dire, c'est de redire et, dans cette redite, de dire encore une première fois." (BLANCHOT, 1969 p. 459)

É com Fórmulas de uma luz inexplicável que Nuno Júdice celebra uma vez mais a noção de poema, esse autêntico pavão sonoro, quarenta anos depois destas duas primeiras invectivas terem iniciado o extenso poema que desde então vem escrevendo. Na mais recente entrevista que lhe fizemos, a propósito do website Poems from the Portuguese, a última pergunta foi a mais revelatória e elucidatória do que motiva verdadeiramente este percurso, do imutável local onde se situa esta poética tão particular. Desta forma, não há melhor poema para começar a falar deste novo livro do que aquele que vigora a meio e que apropriadamente se intitula "Cânone":

Há livros raros na minha memória deles: o general dourakine, que depois troquei pelo lenine; o platero, que é um burro, e sabe mais do que muitos que o não são; os sonetos da florbela, e as fotografias dela. Há os poemas do nobre a passear pela foz, e os do cesário a espreitar burguesas, e uma delas tinha o seio à mostra; há o eurico do herculano e o noivado do sepulcro cantado ao piano. Não sei o que fiz a estes livros, mas ainda me comovem - ou será quem os leu, que já não sei se ainda sou eu, que faz todo o caminho de volta para me abrir as páginas que o tempo colou, uma a uma, até ao fim, sem pensar no que me fazia parar a meio: a louca hermengarda de túnica rasgada, as virgens do nobre ao poente, e aquela burguesa, na merenda do cesário, a mostrar-me o seio.

Poderíamos dividir este poema em duas partes complementares, e que dialogam directamente com os seus poemas e a sua poética particular, tornando-a numa achega significativamente autobiográfica ao seu universo literário. Se por todo o poema se enumeram momentos e actores desse mesmo universo (como por todo o livro), numa segunda parte do poema é de assinalar a assunção claramente pessoal de que o leitor Júdice, como leitor normal que viveu todas essas personagens e livros, guarda a memória deles mais do que guardar um conceito estável de identidade - os livros e as razões porque os lemos, bem como as coisas que neles vemos 
mudam dentro de nós e connosco, apesar de continuarem pelo tempo. Um apontamento ainda a denotar aqui: a escolha em particular de elementos ligados ao feminino, sendo as mulheres as figuras que mais populam os seus poemas e simultaneamente a chave, tantas vezes, dos seus poemas, num tu que se espera, que se eleva, que se ama, e que é a razão última de escrever. Em suma, talvez este seja dos poemas mais recentes de Júdice que, por via da sinédoque, mais directamente dialogam com toda a sua obra, seja do ponto de vista estilístico (sempre a oscilação entre a paródia e a ironia no tratamento das metáforas e das imagens), seja do ponto de vista de conteúdo. Assim, e como seria de esperar, o livro apresenta outras vénus, outras proserpinas e outras didos, mas também um novo édipo e e um novo orfeu (dos melhores poemas do livro, do nosso ponto de vista, é onde escreve sobre Hipaso de Metaponto, [JÚDICE, 2012, p. 20], ou onde relaciona Pessoa com Wilde, em "De profundis”, [JÚDICE, 2012, p. 67]), continuando a ligação judiciana à cultura ocidental de onde parte, apropriando-a num discurso de estilo próprio, por vezes mordaz, como neste "caminho para o inferno".

Há muito que não ouço falar de eneias, como se nunca tivesse existido, ou não ecoasse ainda nos campos de onde partiu a sua voz, chamando pelos deuses. Conheci-o nos cafés de tróia, com a barba por fazer e a roupa de alguns dias, como se não tivesse casa para dormir. "Quando é o próximo barco para o inferno”, perguntava-me. E esvaziava os copos de aguardente que mandava vir, para que eu os pagasse. Até ao dia em que o seu lugar na mesa ficou vazio. "Alguém sabe onde está? Não deu notícias?” Mas nenhum barco abandonara o porto, e só o cão que nunca o deixara andava às voltas da mesa, como se me pedisse que lhe encontrasse o dono. (JÚDICE, 2012, p. 21)

Peguemos nesta imagem final do cão abandonado no porto, como a memória ou o registo que dela faz o poema depois do momento passado. Esta é uma imagem importante no livro, e que subtilmente aparece noutros poemas. Não pensamos ser por acaso. Muito deste novo volume vive desse momento de partida, isto é, de uma morte sempre metaforizada noutras partidas. $\mathrm{E}$ as viagens encontram-se aqui por todo o lado (veja-se os vários lugares referidos, da América do Sul à Índia, até a um "Manual de Viajante" muito particular).

Se a ironia acontece precisamente quando dois tipos de discurso se imiscuem sem se autoexcluir num determinado texto (chez Linda 
Hutcheon), pensamos que tanto podemos sentir estas "partidas" com uma melancolia por essa passagem inexorável do Tempo (melancolia é mesma uma palavra importante neste livro, como em toda a sua obra), mas igualmente com o riso de quem tudo isso decompõe para o superar no momento presente ${ }^{1}$. O mais longo poema destas Fórmulas, "Cartão de Embarque" é disto o melhor exemplo, fazendo par com outros poemas igualmente longos e interdisciplinares da sua obra, como por exemplo "História de Arte" (in Geometria Variável, 2005) ou "Variações inglesas de Constable com As Quatro Estações” (in O Estado dos Campos, 2002). É nisto que Júdice continua a ser mestre sem par no panorama da poesia portuguesa actual: Retira do contexto, analisa, decompondo, complexificando, para de novo dar ao leitor, sempre com as palavras no seu lugar certo, sempre com uma musicalidade interna, sem necessidade de rima, e, também por tudo isso, com uma linguagem acessível a todos. Vale a pena ver o penúltimo poema do livro, "Uma questão terminológica" (JÚDICE, 2012, p. 106), onde vemos bem espelhada a típica estrutura tripartida do poema judiciano, a proposição de um problema, a sua complexificação e desenvolvimento (com apontamento inter- e intratextual de Inês de Castro) e uma conclusão em chave de ouro, antecedida de uma adversativa (porém, mas, no entanto,...). Veja-se como o paradigma da narratividade se sustém e prossegue na sua obra poética através de uma interessante e prolífica aproximação ao conceito de short-story em particular e de prosa em geral. Cada poema, tal como o entendemos numa unidade básica, conta e enreda-se através de uma história, seja ela mais ou menos real, mais ou menos erótica, mais ou menos histórica e/ou mitológica (isto do ponto de vista do intertexto com que estabelece esse tipo de ligação) e/ou mais ou menos irónica/paródica. Tudo na perseguição, sempre volúvel e volátil do que é um poema. Júdice, ecoando aquilo que diz na sua resposta à nossa pergunta, deixa bem claro que esta não é uma procura definitiva ou final e que é precisa a vida toda para a escrever - o poema pode adquirir várias formas, mas sempre escapa a uma definição, e é essa a sua natureza intrínseca. Basta para isso pararmos um pouco e analisarmos todos os elementos que compõem os títulos das suas obras, sobretudo as mais recentes, e atentar na ironia por detrás deles. Sem querer ser exaustivo, Júdice propõe-nos uma "noção" (1972), um "mecanismo" (1975), "regras" (1990), uma "teoria" (1999), uma "cartografia" (2002), um "guia" (2010), chegando às "fórmulas" deste ano. Esse princípio normativo, porém, está sempre ligado a princípios mais subjectivos e indefiniveis, ou não estivéssemos a falar de poemas - "fragmentação" (1975), "perspectiva” (1990), "sentimento" (1999), "emoções” (2002), "variável” (2005), "inexplicável” (2012). Voltando à forma com que iniciei este texto, não posso assim alinhar-me junto dos críticos que, por sacrifício inglório de uma originalidade que não se sabe muito bem o que é e esquecendo um princípio bem mais importante a nosso ver, o da consistência, criticam cegamente a "verborreia" desta obra, e/ou a dividem em fases sem olhá-la mais fundo e mais de fundo.

Voltemos a este livro em particular. Mutatis mutandis, é de um maior carácter pessoal da memória que este livro talvez se aproxime, e ain- 
da que esta seja uma tendência que sempre existiu, aparece mais explicitamente nos últimos livros de Júdice (tenta-se uma aproximação de definição em "Estudo em branco", (JÚDICE, 2012, p. 101), como um lençol branco como a página do poema). Neste sentido, é de notar que, tal como em $\mathrm{Ge}$ ometria Variável (2005), As Coisas Mais Simples (2006) ou Guia de Conceitos Básicos (2010), já de si títulos poeticamente ambíguos como vimos, existem núcleos temáticos directamente relacionados com a sua vivência no sul, na província, nas casas da infância, num outro mundo que existiu quando o autor era criança, mas que, pelo poder da poesia, qualquer leitor pode experimentar e identificar-se. Também se sente uma presença mais forte da religião neste e nos livros mais recentes, seja directamente pela relação com uma "cena biblica" de Jonas e a baleia (JÚDICE, 2012, p. 14), seja indirectamente com a referência a Deus e à criação com a aproximação ao gesto criador do poeta ("Mistérios", p. 66). Veja-se o poema "Nova Suma Teológica”, ligado directamente a "Soma Teológica" de Geometria Variável ou "Enigma Teológico", de O Estado dos Campos. Neste livro em particular, e como já se aflorou, essa memória pessoal adquire uma especial significação quando alguns poemas falam do momento eterno, mas artificial, que uma fotografia invoca (JÚDICE, 2012, p. 48, 49, 50, 53), ou usam a fotografia como metáfora desse mesmo passado actualizado no presente, como “nas primeiras páginas" de um poema (JÚDICE, 2012, p. 72). Dois poemas são importantes neste campo, estabelecendo um verdadeiro diálogo interno - "A visita" (JÚDICE, 2012, p. 36) e talvez mais simbolicamente para todos os outros, "Entre fotografia e poema" (JÚDICE, 2012, p. 43):

Neste esboço, há aquele segmento

do teu rosto, quase a preto e branco, que sai da sombra do táxi; mas faltam as mãos (e sem elas o retrato não fica completo). Na realidade, o corpo parece fragmentado quando o capturamos de surpresa, sem saber o que irá surgir depois do flash. E poderia desenhar-se um cenário puramente abstracto, com um fundo de azulejo a dar um tom clássico à imagem, ou apenas o branco da parede, e neste caso haveria uma contraluz que só deixaria à vista o teu perfil. Porém, quando olho o teu retrato, vejo nele uma presença que posso sentir, e me fala como se estivesses comigo, fazendo-me ouvir a cor da tua voz. E é como se saísses de dentro desta imagem que é pura forma, instante que a palavra reduz à sua duração, gesto imóvel num desvio do olhar para o poema. 
Escolhemos salientar este poema exactamente por indicar aquilo que esta poética tem de melhor: a reflexão sobre o próprio poema. Obviamente que podíamos argumentar que todos os poemas discutem, pela sua propria existência, o conceito de poema, mas Júdice compraz-se em fazê-lo de forma mais explícita, atitude que está na base da criação poética do seu longo poema de quarenta e muitos anos. O momento do poema, isto é, a passagem da mera "fotografia" para o "poema", como diz o sujeito poético, dá-se quando o daguerreótipo da mulher amada sai "de dentro/ desta imagem que é pura forma" quando nele se vê "uma presença que se pode sentir". Vale a pena ilustrar um pouco melhor esse tema, com um outro poema-chave no livro, bem como para toda a sua produção poética. Falo de "Uma relação necessária com o real não o implica" (JÚDICE, 2012, p. 90):

A minha concepção de realismo em poesia não me obriga a falar da realidade quando escrevo o poema, nem a ter as mãos sujas do barro e da lama de que a vida é feita. Mas quando saio de casa, e as ruas me aparecem com a evidência dos seus habitantes, ou quando leio os títulos dos jornais na banca da esquina, essa realidade é outra; não digo que seja mais real do que a do poema, ou que a vida me obrigue a tirar da cabeça o sonho a que pertence a outra realidade do que escrevo. O que posso concluir, porém, é que existe um conflito entre o que vejo e o que, desse olhar, passa para o poema. Posso designá-lo por fractura, e compará-lo com as palavras que, tal como a água que corre nas montanhas, e é limpa pelo filtro invisível da pedra, se deixam purificar pela música do poema, quando nascem do verso, como a água da fonte.

Muito mais se poderia dizer sobre este livro, sobretudo naquilo que ele se remete para com outros marcos da obra judiciana (a cor azul de "O sentido do Azul", [JÚDICE, p. 41], por exemplo), mas em traços gerais, estas fórmulas de uma luz inexplicável são mais um notável degrau na já longa escadaria do poema judiciano, mais uma metáfora com que Nuno Júdice nos brinda na perseguição da noção de poema que o faz escrever desde sempre. Quarenta anos depois, numa poesia que se soube reinventar, renovar caminhos já trilhados, explorar novos trilhos e encontrar-se encore une fois em topos e imagens recorrentes, esta é seguramente uma metapoética sólida e essencial no panorama da literatura portuguesa contemporânea. Esperemos que este texto, eminentemente celebratório deste percurso, seja esse lugar de encontro de quem escreve com quem lê, para dar a ler, 
uma vez mais a um outro leitor, tal como na afirmação incontornável de Blanchot, tal como num poema desta obra.

\section{REFERÊNCIAS BIBLIOGRÁFICAS}

BLANCHOT, Maurice. L'entretien infini. Paris: Gallimard, 1969.

HUTCHEON, Linda, A Theory of Parody: The Teachings of Twentieth-Century Art Forms. Illinois: UIP, 1984.

JUDICE, Nuno. O Estado dos Campos. Lisboa: Dom Quixote, 2002.

. Fórmulas de uma Luz Inexplicável. Lisboa: Dom Quixote, 2012. . Geometria Variável. Lisboa: Dom Quixote, 2005.

. Guia de Conceitos Básicos. Lisboa: Dom Quixote, 2010.

. O Mecanismo Romântico da Fragmentação. Porto: Inova, 1975. . A Noção de Poema. Lisboa: Dom Quixote, 1972.

. O Pavão Sonoro. Lisboa: Dom Quixote, 1972.

. Regras da Perspectiva. Lisboa: Quetzal, 1990.

. Teoria Geral do Sentimento. Lisboa: Quetzal, 1999.

Recebido para publicação em 01/05/12.

Aprovado em 15/06/2012.

\section{NOTA}

1 No entanto, não deixa de fazer apontamentos relativos ao quotidiano mais comum, usando para isso da subversão irónica, roçando por vezes a paródia. A "Pressão dos mercados", que surgiu em primeira mão há alguns meses numa edição do Jornal de Letras, Artes e Ideias, é disso paradigma. 